\title{
Advances in the Surgical Treatment of Faecal Incontinence
}

\author{
Gregory P. Thomas · Carolynne J. Vaizey
}

Published online: 14 March 2013

(C) Springer Science + Business Media New York 2013

\begin{abstract}
Faecal incontinence is a common condition. Once conservative therapy has failed, surgical management of this problem is required. Over the last decade, neuromodulation has emerged as an effective and safe treatment. The most widely used form of neuromodulation is sacral nerve stimulation. The other less commonly used techniques are posterior tibial nerve stimulation and pudendal nerve stimulation. Anterior sphincteroplasty still has an important role to play in selected cases. If these treatments fail, then other therapies need to be considered. Recent advances in anal sphincter bulking agents and artificial sphincter devices offer some hope for these patients.
\end{abstract}

Keywords Faecal incontinence $\cdot$ Neuromodulation $\cdot$ Anal sphincter $\cdot$ Sphincteroplasty $\cdot$ Bulking agents $\cdot$ Advances

\section{Introduction}

Faecal incontinence $(\mathrm{FI})$ is a common condition occurring in $2-20 \%$ of the adult population in the western world [1-4]. It is under-reported, most commonly affecting women over 65 years of age [2]. Once significant colorectal pathology has been excluded, the FI can be assessed. Investigations can identify anatomical and physiological problems. Conservative treatments should be offered initially. These include

G. P. Thomas · C. J. Vaizey $(\bowtie)$

The Sir Alan Parks Unit, Department of Physiology, St Mark's Hospital and Academic Institute, Watford Road, Harrow, Middlesex HA1 3UJ, UK

e-mail: cvaizey@nhs.net anti-diarrhoeal medications, the use of a pad or anal plug and biofeedback [5]. More invasive treatments are reserved for those who fail. They can include injectable anal sphincter bulking agents, radiofrequency ablation (SECCA), sphincter repair, neuromodulation and neosphincter implantation. With the exception of sphincter repair in selected patients and neuromodulation, these treatments generally offer poor results. The majority of the recent literature addressing the management of FI has focussed on neuromodulation. Sacral nerve stimulation (SNS) [6-9] is the most studied modality; the use of other more peripheral nerves including the pudendal $[10,11]$ and posterior tibial nerves is now being investigated [12].

\section{Injectable Anal Sphincter Bulking Agents}

The first report of an injectable bulking agent to treat faecal incontinence was published in 1993 [13]. This was performed using a Teflon-like material. Since then many different materials have been trialled. The results of these have generally been disappointing, mostly due to poor efficacy and safety concerns [14]. Ratto and colleagues recently reported short term results of an injectable polyacrylonitrile, the Gatekeeper ${ }^{\mathrm{TM}}[15 \bullet]$. A thin cylinder of the material is injected into the intersphincteric space and expands over several weeks. Episodes of passive incontinence improved from 7.1 (7.4) at baseline to $0.4(0.6)$ at 33.5 (12.4) months mean follow up. This improvement was also reflected in the quality of life measurements. No adverse effects were reported. Although the study population was small $(n=14)$, these results are promising. Larger studies are ongoing to further define the efficacy and safety profile of this product. 


\section{Radiofrequency Ablation Techniques (SECCA)}

The SECCA system (Curon Medical Inc, Sunnyvale, CA, USA) works by delivering radiofrequency energy to the muscle of the anal canal to induce fibrosis, so that anal canal closure is improved. It is primarily used for passive FI. It is an outpatient procedure and can be performed under local anaesthesia with sedation. In 2002 Takahsahi et al. [16] reported its use in ten patients with idiopathic FI. At 6 months a significant improvement in the Wexner FI score was seen (13.5 to 5). Less impressive improvements in the Wexner FI score were reported by Efron in 2003 [17], Lefebure in 2008 [18] and Ruiz in 2010 [19], of 14.5 to $11.1,14.07$ to 12.33 and 15.6 to 12.9 , respectively. These results indicate that the patients remained moderately incontinent after treatment. It would appear that the SECCA system offers only a marginal benefit.

\section{Anal Sphincteroplasty}

The overlapping sphincter repair is the operation of choice for patients with a full length external anal sphincter defect who have good residual sphincter muscle activity. A recent systematic review has examined the long term outcome of this operation [20]. This reviewed the outcome of over 900 patients at five or more years of follow up. The authors found that there was marked heterogeneity of the objective measures of incontinence used. They did, however, note an initial improvement followed by a gradual deterioration in symptoms over time. Interestingly this deterioration did not appear to correlate with an adverse change in quality of life or patient satisfaction measures. No consistent predictive factors for failure were identified.

\section{Neuromodulation}

\section{Sacral Nerve Stimulation}

Sacral nerve stimulation (SNS) is the most established form of neuromodulation for FI. The first description of its use for FI was in 1995 [21]. There are now a multitude of reports describing its efficacy in the short and medium term. The SNS involves the delivery of electrical stimulation to the third sacral nerve root. Initially, patients undergo a 2 or 3 week period of peripheral nerve evaluation (PNE) with a percutaneous insertion of a stimulating electrode (Medtronic, Minneapolis, MN) into the sacral foramen. The patient maintains a bowel diary before and during the evaluation period. A clinically successful improvement during the evaluation phase is commonly defined as at least a $50 \%$ reduction in frequency of incontinent episodes based on review of the patient's bowel diary. Patients who demonstrate such an improvement are offered a permanently implanted stimulator.

A recent prospective report of 50 patients treated with SNS described a PNE failure rate of $20 \%$. Of those that received permanent stimulation, $20 \%$ failed to regain the benefit experienced during the evaluation phase. Of 37 patients who underwent placement of a permanent SNS, 14 had a $50 \%$ reduction in incontinent episodes and 13 became continent [22]. These outcomes are not as favourable as those previously reported, in which PNE was successful in up to 90 and $80 \%$ experienced a reduction in incontinent episodes [23].

Reports describing the outcome of SNS in the longer term are now emerging. These suggest an improvement in symptoms can be achieved after 5 years and longer. However, there does appear to be some loss of efficacy over time [9, 24]. It is not clear why this should be, or what the predictive factors are. Sacral nerve stimulation (SNS) is the only current treatment with efficacy comparable to sphincteroplasty. The SNS is effective in those with an external sphincter defect [25]. To date there are no published reports directly comparing these two treatments.

There has always been debate as to the mechanisms underlying the efficacy of neuromodulation. Initially it was thought the effects were focussed solely upon the anal sphincter mechanism and the rectum. However, it is now believed that SNS has multiple different physiological effects $[26,27]$. These include modulation of local somatovisceral reflexes leading to changes in colonic motility and internal anal sphincter activity, and also modulation of a higher perception of afferent information.

Giani et al. [28•] described an increase in the latency of cerebral somatosensory that evoked potentials in patients with faecal incontinence and constipation undergoing SNS. Griffin et al. [29] examined the effects of posterior tibial nerve stimulation and SNS on the somatosensory cortex in an animal model. During stimulation an increase in amplitude of primary cortical evoked potentials was seen suggesting that neuromodulation can alter the representation of the lower gastrointestinal tract in the sensory cortex.

It has been shown that colonic motility appears to slow during SNS for FI [30]. However when used for slow transit constipation the opposite appears to be the case [31]. The consensus has been that the amplitude of SNS should be set at a sub-sensory level. However, recent work has shown there to be a further increase in colonic motility when SNS is set at a supra-sensory level in patients with slow transit constipation [32]. The effects of supra-sensory stimulation have not yet been reported in those with FI. It has been shown that reducing the amplitude down to $25 \%$ of sensory threshold level does not appear to adversely influence the efficacy of SNS for FI [33]. 
The SNS is typically delivered with a variable amplitude and electrode setting and with a fixed pulse width and frequency, of $210 \mu \mathrm{s}$ and $14 \mathrm{~Hz}$, respectively. These settings date back to the original description of SNS. Dudding et al. [34] suggested that an improvement could occur by increasing the frequency and reducing the pulse width. Recent work has confirmed a greater reduction in incontinent episodes when a higher frequency was used [35]. Ongoing research into the way SNS works is now required, so that its efficacy can be improved.

\section{Posterior Tibial Nerve Stimulation}

Posterior tibial nerve stimulation (PTNS) for FI was first described by Shafik in 2003 [12]. Since then 12 non-comparative studies have reported its use. The PTNS can be delivered using a needle electrode (percutaneous) or an electrode pad (transcutaneous). The published literature suggests that it is an effective treatment. Percutaneous PTNS appears to be more efficacious than transcutaneous PTNS [36]. However, percutaneous PTNS requires hospital based administration, whilst transcutaneous PTNS can be self-administered by the patient at home. The PTNS is cheaper than SNS in the short term. It is also safer and does not require an operation.

It is thought that PTNS works by remote neuromodulation of the sacral plexus. However, the superficial position of the posterior tibial nerve by the ankle also corresponds to an acupuncture point called sanyinjiao. A small pilot study by Scaglia et al., in 2009 [37], showed that there was some improvement in symptoms of faecal incontinence using acupuncture. The sanyinjiao point was one of the acupuncture points used. No work published so far has directly compared acupuncture and PTNS.

The largest series of PTNS was reported by Hotouras et al., in 2011 describing the short term outcome in 100 patients with urge, passive and mixed FI [38]. The PTNS was administered either once weekly or twice weekly, for 12 and 6 weeks, respectively. Patients with urge and mixed FI demonstrated a statistically significant improvement in the mean Cleveland Clinic Florida-FI incontinence scale. For those with mixed FI $(n=60)$, the frequency of incontinent episodes fell from $5(0-35)$ to $1(0-27), p \leq 0.0001$. For urge FI $(n=25)$ the number of episodes improved from $4(0-30)$ to $0(0-10), p=0.0047$. For passive FI, there was no significant improvement, $4(0-21)$ to $3(0-21), p=0.2839$. These results compare favourably to those of SNS in the short term. However, there has been no medium or long term assessment of PTNS. More importantly there are no studies comparing PTNS with SNS, or with any other established therapies. There is no consensus as to what the optimum treatment regime should be. The published literature describes a wide range of differing treatment regimes and outcome reporting measures. As stated earlier, percutaneous PTNS does require ongoing specialist delivered treatment. Therefore, in the longer term, the costs of PTNS may begin to equal that of SNS. More work is needed to ascertain the optimum treatment regime for PTNS, and to establish its position in the treatment pathway of FI. The PTNS may become the firstline neuromodulation modality, because of its ease of use, safety and initial low costs. SNS could then be reserved for those who require long term treatment or for those who fail to respond sufficiently.

Pudendal Nerve Stimulation

Pudendal nerve stimulation (PNS) involves the direct stimulation of the pudendal nerve. Its theoretical advantage is that the nerve roots $S 2,3$ and 4 are stimulated at once (rather than just S3), so the number of activated afferent pathways is increased. This is achieved percutaneously, by either a trans-gluteal or an infra-gluteal approach. Like SNS, it requires a test period prior to permanent stimulation. Most of the published literature describes its use for urinary tract dysfunction. At present, only a few reports have described PNS as a treatment for FI. The first was a two patient case series in 2010 [10]. In 2011 George et al. [39] reported its use in seven patients who had had a poor response to SNS. Five of the seven had a greater than $50 \%$ improvement in episodes of FI, 14 (10.7) at baseline to 7 (7.2). An improvement in defecatory deferral time was also seen, 2 (0.74) minutes to 6 (5.8) minutes. The outcome of PNS in patients with faecal incontinence and cauda equina syndrome was also recently reported [40]. Five patients underwent stimulation. All experienced a greater than $50 \%$ reduction in incontinent episodes, $9(10.4)$ at baseline to $0(0.5)$. There was also an improvement in the defecatory deferral time from 2 (1.8) at baseline to 11 (5.5) minutes.

Peters et al. [41] conducted a single-blinded cross-over study comparing PNS with SNS for urinary incontinence. They found that PNS was a more effective treatment for interstitial cystitis. No work has yet been reported to directly compare the effects of PNS with SNS for FI. It is uncertain there will be a significant difference in efficacy between the two. PNS is a more difficult procedure to perform. Because of this, we feel that PNS is unlikely to replace SNS for those with non-neurogenic FI. Instead, we would suggest that PNS is likely to be reserved for those whose symptoms are refractory to SNS. Such an approach has already been proposed for urinary tract dysfunction [42].

\section{Artificial Anal Sphincter}

AMS 800 and Acticon Neosphincter

The use of an artificial anal sphincter for FI was first reported in 1987 [43]. This utilized the AMS 800 device, 
which had originally been devised for urinary incontinence. Many reports have further described its efficacy, and later on, that of the Acticon neosphincter [44-50].

The common mechanism for these devices is an inflated cuff which encircles the sphincter complex. The patient is able to deflate the cuff using a pump located in the labia majora or scrotum when defecation is desired. A systematic review [51] analysed the outcome from 14 reports. This found a very high incidence of device removal mostly due to erosion, infection or device failure. It is worth noting that few of the reports included in this review analysed their data on an intention to treat basis. Those patients who were left with a functioning implant had a significant improvement in their symptoms. These conclusions were reflected in a recent report describing the outcome of 52 patients, who had been implanted with the Acticon device over a 14 year period [52]. At a mean follow up of 64.3 (46.5) months, $26 \%$ had undergone removal of their device, the majority secondary to infection. Twenty four percent underwent revision, due to device failure. Of those left with a functioning device, $67.3 \%$ had a significant improvement in the Cleveland Clinic Florida-FI score and in quality of life scores.

\section{The Prosthetic Anal Sphincter}

The outcome of another device, called the prosthetic anal sphincter (PAS), was reported in 2004 [53]. This expandable device is placed at the anorectal junction, and acts to accentuate the effect of puborectalis, by narrowing the angle between the rectum and anus. The PAS can be controlled by the patient, so allowing the anorectal angle to straighten when defecation is desired. In this report 12 patients had PAS implanted. At a median follow up of 59 (30-72) months, ten of these patients became continent. The Cleveland Clinic Florida-FI score improved from 16 (7-20) at baseline to $3(0-7)$. Two of these devices were explanted due to infection following revisional surgery. Despite this, the reported improvement in symptoms is encouraging.

\section{The Magnetic Anal Sphincter}

A new device has emerged recently, called the magnetic anal sphincter. This comprises a flexible ring of magnetic titanium beads. This had initially been used to treat gastrooesophageal reflux. The device is placed to encircle the external anal sphincter. The beads come together, due to their magnetism, and close the anus. The pressure exerted by voluntary defecation is enough to separate the beads, and thus open the anus. A preliminary report described its use in 14 patients [54]. Three of these patients had their devices explanted. At a median follow up of 6 months, five patients had a significant reduction in incontinent episodes of 7.2 at baseline to 0.7 , with a significant improvement in quality of life scores.

A small non-randomised study compared the outcome of the magnetic anal sphincter $(n=10)$ with the Acticon device $(n=10)$ [55]. Four of the Acticon devices were revised, two of these were explanted due to infection. One of the magnetic anal sphincters spontaneously explanted. Overall a significant reduction in the Cleveland Clinic Florida-FI score was seen in both groups. The SNS was compared to the magnetic anal sphincter in a similar fashion [56]. Both therapies achieved a significant reduction in episodes of incontinence and improvements in quality of life measures were also seen. In both studies, it is likely that multiple reporting of the same patient outcome has taken place. These studies are non-randomised and small; therefore, it is difficult to draw any firm conclusions. Larger, truly prospective randomised trials are needed to accurately determine the efficacy and safety of the magnetic anal sphincter.

\section{Conclusions}

Neuromodulation and, in some cases, sphincteroplasty are the first choice therapies for those who fail conservative treatments for FI. Currently the neuromodulation modality of choice is sacral nerve stimulation. Further studies to evaluate the roles of posterior tibial nerve stimulation and pudendal nerve stimulation are needed. The real challenge comes when the clinician is presented with a patient who has failed these measures. Although some will benefit from a stoma, consideration should be given to the use of sphincter bulking agents and artificial anal sphincters. The artificial anal sphincters potentially have a high complication rate, and should be reserved only for those who are truly "end-stage", and for whom the only other option is a stoma.

Disclosure Gregory P. Thomas and Carolynne J. Vaizey declare that they have no conflicts of interest.

\section{References}

Papers of particular interest, published recently, have been highlighted as:

- Of importance

1. Perry S, et al. Prevalence of faecal incontinence in adults aged 40 years or more living in the community. Gut. 2002;50(4): $480-4$.

2. Nelson R, et al. Community-based prevalence of anal incontinence. JAMA, J Am Med Assoc. 1995;274(7):559-61. 
3. Ho YH, et al. Faecal incontinence: an unrecognised epidemic in rural North Queensland? Results of a hospital-based outpatient study. Aust J Rural Health. 2005;13(1):28-34.

4. Goode PS, et al. Prevalence and correlates of fecal incontinence in community-dwelling older adults. J Am Geriatr Soc. 2005; 53(4):629-35.

5. Maslekar S, et al. Investigation and treatment of faecal incontinence. Postgrad Med J. 2006;82(968):363-71.

6. Jarrett ME, et al. Sacral nerve stimulation for faecal incontinence in the UK. Br J Surg. 2004;91(6):755-61.

7. Matzel KE, et al. Sacral spinal nerve stimulation for faecal incontinence: multicentre study. Lancet. 2004;363(9417):1270-6.

8. Hollingshead JR, Dudding TC, Vaizey CJ. Sacral nerve stimulation for faecal incontinence: results from a single centre over a 10-year period. Colorectal Dis. 2011;13(9):1030-4.

9. George AT, et al. Long-term outcomes of sacral nerve stimulation for fecal incontinence. Dis Colon Rectum. 2012;55(3): 302-6.

10. Bock S, et al. First experiences with pudendal nerve stimulation in fecal incontinence: a technical report. Tech Coloproctol. 2010;14(1):41-4.

11. George AT, Dudding TC, Kamm MA, Spinelli M, Nicholls RJ, Vaizey CJ. Pudendal nerve stimulation for bowel dysfunction secondary to spinal cord injury. Colorectal Dis. 2011;13(1): 117-20.

12. Shafik A, et al. Percutaneous peripheral neuromodulation in the treatment of fecal incontinence. Eur Surg Res. Europaische chirurgische Forschung. Recherches chirurgicales europeennes. 2003;35(2):103-7.

13. Shafik A. Polytetrafluoroethylene injection for the treatment of partial fecal incontinence. Int Surg. 1993;78(2):159-61.

14. Maeda, Y., S. Laurberg, and C. Norton, Perianal injectable bulking agents as treatment for faecal incontinence in adults. Cochrane database of systematic reviews, 2010(5): p. CD007959.

15. - Ratto $\mathrm{C}$, et al. Novel bulking agent for faecal incontinence. Br J Surg. 2011;98(11):1644-52. This report and that by Lehur et al. [46] describe the outcome of two novel devices (the "Anal Gatekeeper" and the "Magnetic Anus"). Although both are small studies, they suggest great promise. Larger studies are needed to further investigate these devices' efficacy and safety.

16. Takahashi $\mathrm{T}$, et al. Radio-frequency energy delivery to the anal canal for the treatment of fecal incontinence. Dis Colon Rectum. 2002;45(7):915-22.

17. Efron JE, et al. Safety and effectiveness of temperature-controlled radio-frequency energy delivery to the anal canal (Secca procedure) for the treatment of fecal incontinence. Dis Colon Rectum. 2003;46(12):1606-16. (discussion 1616-8).

18. Lefebure B, et al. Temperature-controlled radio frequency energy delivery (Secca procedure) for the treatment of fecal incontinence: results of a prospective study. Int J Colorectal Dis. 2008; 23(10):993-7.

19. Ruiz D, et al. Does the radiofrequency procedure for fecal incontinence improve quality of life and incontinence at 1-year follow-up? Dis Colon Rectum. 2010;53(7):1041-6.

20. Glasgow SC, Lowry AC. Long-term outcomes of anal sphincter repair for fecal incontinence: a systematic review. Dis Colon Rectum. 2012;55(4):482-90.

21. Matzel KE, et al. Electrical stimulation of sacral spinal nerves for treatment of faecal incontinence. Lancet. 1995;346(8983):1124-7.

22. Boyle DJ, et al. Efficacy of sacral nerve stimulation for the treatment of fecal incontinence. Dis Colon Rectum. 2011;54(10): $1271-8$

23. Wexner SD, et al. Sacral nerve stimulation for fecal incontinence: results of a 120-patient prospective multicenter study. Ann Surg. 2010;251(3):441-9.
24. Lim JT, et al. Sacral nerve stimulation for fecal incontinence: long-term outcomes. Dis Colon Rectum. 2011;54(8):969-74.

25. Ratto C, et al. Sacral nerve stimulation in faecal incontinence associated with an anal sphincter lesion: a systematic review. Colorectal Dis. 2012;14(6):e297-304.

26. Matzel KE. Sacral nerve stimulation for faecal incontinence: its role in the treatment algorithm. Colorectal Dis. 2011;13(Suppl 2): $10-4$.

27. Gourcerol G, et al. How sacral nerve stimulation works in patients with faecal incontinence. Colorectal Dis. 2011;13(8): e203-11.

28. - Giani I, et al. The effect of sacral nerve modulation on cerebral evoked potential latency in fecal incontinence and constipation. Ann Surg. 2011;254(1):90-6. This study and that by Griffin et al. [29] provide an interesting insight into how neuromodulation may work. They point to a new direction of research into neuromodulation's mechanism of action.

29. Griffin KM, et al. Sacral nerve stimulation increases activation of the primary somatosensory cortex by anal canal stimulation in an experimental model. Br J Surg. 2011;98(8):1160-9.

30. Michelsen HB, et al. Rectal motility after sacral nerve stimulation for faecal incontinence. Neurogastroenterol Motil. 2010;22(1): 36-41.

31. Dinning PG, et al. Sacral nerve stimulation induces pan-colonic propagating pressure waves and increases defecation frequency in patients with slow-transit constipation. Colorectal Dis. 2007;9(2): 123-32.

32. Dinning PG, et al. Pancolonic motor response to subsensory and suprasensory sacral nerve stimulation in patients with slow-transit constipation. Br J Surg. 2012;99(7):1002-10.

33. Duelund-Jakobsen J, Buntzen S, Lundby L, Laurberg S. Sacral nerve stimulation at sub-sensory threshold does not compromise treatment efficacy - results from a randomised blinded cross-over study. Ann Surg. 2013;257(2):219-23.

34. Dudding TC, et al. Improving the efficacy of sacral nerve stimulation for faecal incontinence by alteration of stimulation parameters. Br J Surg. 2009;96(7):778-84.

35. Duelund-Jakobsen J, Dudding TC, Bradshaw EB, Buntzen S, Lundby LL, Laurberg SL, Vaizey CJ. Sacral nerve stimulation for faecal incontinence with alternative pacemaker settings can improve patient satisfaction and treatment outcome-results of a randomised double-blind cross-over study. Br J Surg. 2012;99(10): 1445-52.

36. George AT, Kalmar K, Sala S, Panarese A, Kokopoulis K, Nicholls RJ, Vaizey CJ. A prospective single blinded placebo controlled study into the role of percutaneous and transcutaneous for the treatment of faecal incontinence. Colorectal Dis. 2011;54(4): 1-14. (02).

37. Scaglia M, et al. Fecal incontinence treated with acupuncture-a pilot study. Auton Neurosci. 2009;145(1-2):89-92.

38. Hotouras A, et al. Short-term outcome following percutaneous tibial nerve stimulation (PTNS) for faecal incontinence: a singlecentre prospective study. Colorectal Dis. 2012;14(9):1101-5.

39. George AT, D.T.C., Nicholls RJ, Viazey CJ. Pudendal nerve stimulation for faecal incontinence in patients who have failed sacral nerve stimulation. Gut. 2011;60(Supp):A156.

40. George AT, D.T.C., Nicholls RJ, Viazey CJ. Pudendal nerve stimulation for bowel dysfunction incomplete cauda euqina patients. Gut. 2011;60(Suppl 1):A155-6.

41. Peters KM, Feber KM, Bennett RC. A prospective, single-blind, randomized crossover trial of sacral vs. pudendal nerve stimulation for interstitial cystitis. BJU Int. 2007;100(4):835-9.

42. Peters KM, et al. Chronic pudendal neuromodulation: expanding available treatment options for refractory urologic symptoms. Neurourol Urodyn. 2010;29(7):1267-71. 
43. Christiansen J, Lorentzen M. Implantation of artificial sphincter for anal incontinence. Lancet. 1987;2(8553):244-5.

44. Vaizey CJ, et al. Clinical, physiological, and radiological study of a new purpose-designed artificial bowel sphincter. Lancet. 1998; 352(9122):105-9.

45. Lehur PA, et al. Results of artificial sphincter in severe anal incontinence. Report of 14 consecutive implantations. Dis Colon Rectum. 1996;39(12):1352-5.

46. Wong WD, et al. Artificial anal sphincter. Dis Colon Rectum. 1996;39(12):1345-51.

47. Altomare DF, et al. Multicentre retrospective analysis of the outcome of artificial anal sphincter implantation for severe faecal incontinence. Br J Surg. 2001;88(11):1481-6.

48. Devesa JM, et al. Artificial anal sphincter: complications and functional results of a large personal series. Dis Colon Rectum. 2002;45(9):1154-63.

49. Wong WD, et al. The safety and efficacy of the artificial bowel sphincter for fecal incontinence: results from a multicenter cohort study. Dis Colon Rectum. 2002;45(9):1139-53.

50. Michot F, et al. Artificial anal sphincter in severe fecal incontinence: outcome of prospective experience with 37 patients in one institution. Ann Surg. 2003;237(1):52-6.
51. Mundy L, et al. Systematic review of safety and effectiveness of an artificial bowel sphincter for faecal incontinence. Br J Surg. 2004;91(6):665-72.

52. Wong MT, et al. The artificial bowel sphincter: a single institution experience over a decade. Ann Surg. 2011;254(6):951-6.

53. Finlay IG, Richardson W, Hajivassiliou CA. Outcome after implantation of a novel prosthetic anal sphincter in humans. Br J Surg. 2004;91(11):1485-92.

54. Lehur PA, et al. Magnetic anal sphincter augmentation for the treatment of fecal incontinence: a preliminary report from a feasibility study. Dis Colon Rectum. 2010;53(12):1604-10.

55. Wong MT, et al. The magnetic anal sphincter versus the artificial bowel sphincter: a comparison of 2 treatments for fecal incontinence. Dis Colon Rectum. 2011;54(7):773-9.

56. Wong MT, et al. Does the magnetic anal sphincter device compare favourably with sacral nerve stimulation in the management of faecal incontinence? Colorectal Dis. 2012;14(6):e323-9. 